\title{
TRADUÇÃO E ADAPTAÇÃO DO COGNITIVE RESERVE INDEX QUESTIONNAIRE (CRIQ)
}

Adriane Ribeiro Teixeira; Universidade Federal do Rio Grande do Sul e Universidade Federal de São Paulo; adriane.teixeira@gmail.com

Nicole Domingos dos Santos; Universidade Federal do Rio Grande do Sul; nicoledomingos.s@gmail.com Mariana Dann Gamarra; Universidade Federal do Rio Grande do Sul; marianadanngamarra@gmail.com Liliane Desgualdo Pereira; Universidade Federal de São Paulo; lilidesgualdo@gmail.com

\section{RESUMO}

Introdução: A Reserva Cognitiva (RC) é a capacidade cerebral construída ao longo da vida e que pode minimizar os danos clínicos advindos de um processo degenerativo, tais como as demências. Apresenta relação com a neuroplasticidade cerebral e pode ser avaliada por meio de questionários. Um destes é o Cognitive Reserve Index questionnaire (CRIq). Objetivo: relatar o processo de tradução e adaptação cultural do CRIq. Métodos: o questionário, originalmente em italiano, foi traduzido para o português por dois tradutores independentes. A partir destas duas traduções foi elaborada uma versão em português. Esta versão foi retrotraduzida para o italiano, por outros dois tradutores e comparada ao instrumento original. A versão em português foi aplicada a 30 indivíduos, sendo solicitado que apontassem sugestões. Na sequência, o CRIq em português foi apreciado por especialistas, para que apontassem modificações. Resultados: Foram mantidos o mesmo número de questões do original, para a avaliação de atividades relativas a escolaridade, trabalho e tempo livre. Os indivíduos que responderam ao instrumento inicial eram de ambos os sexos, tinham de 19 a 73 anos (média 39,13 12,97 anos) com níveis sócio-econômicos e de escolaridade variados. Eles não sugeriam modificações. Houve correlação entre a RC e a escolaridade $(p=0,00)$. Os especialistas sugeriram termos para serem usados na seção tempo livre, devido às diferenças nas atividades de lazer na Itália e no Brasil. Conclusão: Foi concluída a tradução e adaptação semântica e de conteúdo do CRIq, sendo que o estudo inicial confirmou a rápida e prática aplicação do mesmo.

Palavras-chave: Idoso; Cognição; Reserva Cognitiva.

Fomento: FAPERGS (Bolsa de Iniciação Científica de Nicole Domingos dos Santos) e PROREXT/UFRGS (Bolsa de Extensão Mariana Dann Gamarra).

Agradecimentos: Os autores agradecem à FAPERGS e à PRPREXT/UFRGS pelas bolsas de iniciação científica e extensão universitária concedidas às acadêmicas de graduação. 